Article

\title{
Optimal Operation of Critical Peak Pricing for an Energy Retailer Considering Balancing Costs
}

\author{
Hye Yoon Song, Gyu Sub Lee *(1) and Yong Tae Yoon \\ Department of Electrical and Computer Engineering, Seoul National University, 1 Gwanak-ro, Gwanak-gu, \\ Seoul 08826, Korea; hysong@snu.ac.kr (H.Y.S.); ytyoon@snu.ac.kr (Y.T.Y.) \\ * Correspondence: lgs1106@snu.ac.kr; Tel.: +82-10-4816-5167
}

Received: 30 September 2019; Accepted: 6 December 2019; Published: 7 December 2019

check for updates

\begin{abstract}
Recently, there have been frequent fluctuations in the wholesale prices of electricity following the increased penetration of renewable energy sources. Therefore, retailers face price risks caused by differences between wholesale prices and retail rates. As a hedging against price risk, retailers can utilize critical peak pricing (CPP) in a price-based program. This study proposes a novel multi-stage stochastic programming (MSSP) model for a retailer with self-generation photovoltaic facility to optimize both its bidding strategy and the CPP operation, in the face of several uncertainties. Using MSSP, decisions can be determined sequentially with realization of the uncertainties over time. Furthermore, to ensure a global optimum, a mixed integer non-linear programming is transformed into mixed integer linear programming through three linearization steps. In a numerical simulation, the effectiveness of the proposed MSSP model is compared with that of a mean-value deterministic model based on a rolling horizon method. We also investigate the optimal strategy of a retailer by changing various input parameters and perform a sensitivity analysis to assess the impacts of different uncertain parameters on the retailer's profit. Finally, the effect of the energy storage system on the proposed optimization problem is investigated.
\end{abstract}

Keywords: critical peak pricing; demand response; retailer; multi-stage stochastic programming; rolling horizon method

\section{Introduction}

Recently, renewable energy sources (RESs) have been introduced to the power system of several countries, supported by political investment. However, fluctuation in wholesale electricity prices has increased because of the intermittent nature of generation from RESs [1]. By contrast, the retail market generally offers flat pricing or block pricing, because customers cannot continuously respond to price fluctuations [2]. Therefore, retailers who secure energy in the wholesale market to serve the demand of customers face price risks caused by the difference between wholesale prices and retail rates. This is a challenge for retailers trying to maximize profits [3].

To hedge the price risk, retailers can undertake several strategies such as power purchase agreements, optimizing self-generation portfolio, and financial contracts on the secondary market. Among the hedging methods, implementing an electricity sales plan in the retail market is generally the adopted method in restructured electricity markets [4]. This can be accomplished through the optimal operation of a demand response program, which is divided into two categories: Incentive-based programs (IBPs) and price-based programs (PBPs) [5,6]. Using IBPs, retailers provide incentive payments to customers depending on the amount of reduced load. To measure demand reduction, retailers should determine the customer baseline load (CBL), which varies significantly depending on the evaluation method. Therefore, a fundamental weakness of the IBP is that there is no reliable baseline [7]. By contrast, the PBP is based on dynamic pricing, with higher rates during peak periods 
than off-peak periods. Customers participating in a PBP voluntarily reduce their power consumption in response to time-varying price signals. Pricing methods are typically divided into three types: Real-time pricing (RTP), time-of-use (TOU) pricing, and critical peak pricing (CPP) [5]. RTP is the most economically efficient pricing to hedge against price risk because retail rates can directly reflect the variations in wholesale prices [7]. However, customers find it difficult to participate in RTP because of continuously changing rates. Compared to RTP, TOU is easily accepted by customers because it has a simple rate structure, which divides a day into several blocks and charges a constant rate in each block. With TOU, however, it is difficult to induce customers to reduce demand during critical peak periods [8]. By contrast, CPP has several advantages over the other two pricing models. For example, CPP can be easily implemented because it is based on the rate structure of TOU [9]. Likewise, it can enhance a customer's price responsiveness by applying an extremely high rate during critical peak periods [10].

Although several studies analyze the responses of various demand types under CPP with experimental data [11-16], only a few have investigated the implementation of CPP. In Joo et al. [17], a retailer decides, using a method similar to a swing option problem, when to call a critical event to maximize profit. Park et al. [18] proposed guidelines for designing various parameters in CPP, such as optimal peak rates, event duration, and number of events. In addition, the optimal schedule of critical events was determined. Park et al. [19] investigated the impact of the payback phenomenon on the optimal schedule of critical events and the optimal peak rate. Zhang et al. [20] proposed a decision model to determine critical events by considering the interests of both customers and retailers. This model is deterministically re-calculated daily based on day-ahead price updates for the remaining scheduling horizon. In Chen et al. [21], dynamic thresholds to trigger critical events are computed daily through dynamic programming based on probability distributions of temperature and price. Moreover, Zhang [22] used a stochastic approach to decide the optimal schedule of critical events by formulating an objective function as a mixed integer non-linear programming (MINLP) problem. However, previous studies have not fully analyzed the impact of balancing cost on the CPP operation.

By contrast, in most power markets, the balancing cost is allocated not only to the generation company, but also to the retailer to motivate each to reduce their own variability and uncertainty [23]. The power exchange for frequency control (PXFC) market first proposed in [24] has been investigated in several studies to evaluate the optimal strategy of market participants with balancing cost $[23,25,26]$. In a PXFC market, the balancing cost is allocated to each retailer based on a cost-causality principle in the form of a band capacity purchase [25]. Therefore, we assume the PXFC market circumstance to consider the impact of the balancing cost on strategy of retailer.

In this study, we propose an optimal strategy for a retailer who owns a self-generation facility to maximize its expected profit. The problem is formulated to optimize both the bidding schedule in the PXFC market and the CPP operation in the retail market. Unlike previous works, we introduce a multi-stage stochastic problem (MSSP), incorporating the retailer's uncertainties such as electricity price, demand, and photovoltaic (PV) generation, represented by multiple scenarios. In contrast to a mean-value deterministic stochastic model, MSSP can make decisions sequentially with the uncertainties revealed over periods. Thus, successive decisions can be modified through future observation of uncertainties. Based on the rolling horizon (RH) method, we identify the effectiveness of the proposed MSSP model compared with that of a mean-value deterministic model. Moreover, the MINLP is reformulated as a mixed integer linear problem (MILP) to ensure a global optimum.

The contributions and novelty of the proposed method can be summarized as follows: (1) We suggest an optimization problem to determine the bidding strategy and schedule critical events to maximize the expected profit of retailers considering balancing costs; (2) we develop an MSSP for decisions to be taken recursively with the realization of uncertainties; (3) we linearize the non-linear problem with a binary variable; (4) we analyze the impact of various parameters on the retailer's optimal strategy and profit. 
The rest of the paper is organized as follows. Section 2 introduces the background of this study, including the PXFC market, CPP, and MSSP based on the RH method. Section 3 presents the mathematical formulation of MSSP and the proposed algorithm based on the RH method. Section 4 provides a numerical simulation and discusses the results obtained from various case studies. Finally, Section 5 provides the concluding remarks and future research directions.

\section{Background}

\subsection{The PXFC Market}

In the PXFC market, all market participants, including generation companies and retailers, bid for energy and a band capacity on an hourly basis. Energy is exchanged based on anticipated supply and demand, as in a conventional day-ahead energy market. In addition, market participants purchase band capacity as a reserve capacity to prepare for maximum deviation from the energy. In this respect, balancing cost is allocated in the cost-causality principle. Similar as the PXFC market, Australian Energy Market Operator (AEMO) allocates balancing cost based on the cost-causality principle by utilizing a performance index, indicating the impact of power deviation of each participant on frequency deviation [27]. Figure 1 shows an example of energy and band capacity bids in a PXFC market. Specifically, the reserve capacity used for frequency control is determined in the form of a band capacity purchase in the PXFC market. If the imbalance of each market participant exceeds the band capacity, a penalty price is imposed on the amount of violation. This makes all market participants try to meet their energy schedule. In addition, based on the amount of band capacities purchased from market participants, the system operator estimates the total power imbalance in the system to procure an appropriate amount of reserve [25].

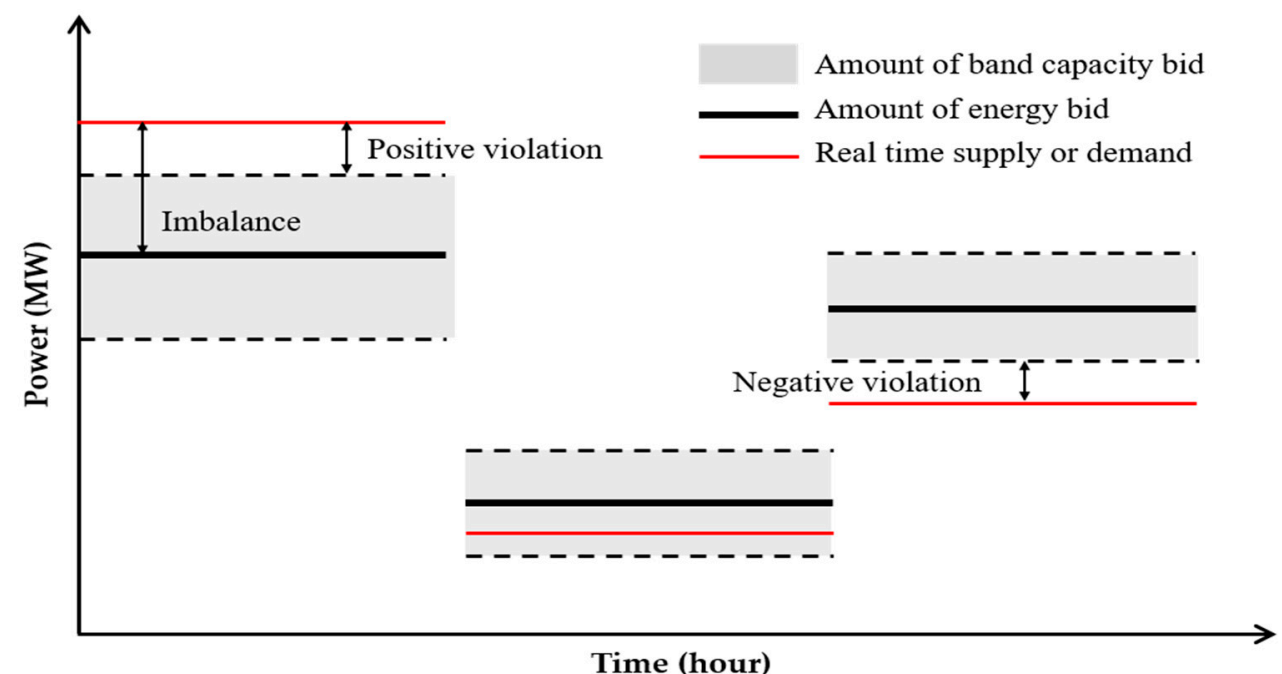

Figure 1. Example of energy and a band capacity bid in the power exchange for frequency control market.

In this study, the retailer's balancing cost is represented as the purchasing cost of a band capacity in the PXFC market. Consequently, the PXFC market allows retailers to plan an optimal strategy in advance, reflecting their anticipated imbalance.

\subsection{Description of CPP}

The rate structure in CPP is designed to encourage reduced consumption by triggering critical events during periods of high wholesale market prices. When a critical event occurs, a pre-specified high retail price is imposed on the customer. Retailers can hedge against price risk caused by a flat rate in the retail market [18]. However, critical events are limited to a certain number of hours per year or month [9]. Therefore, retailers should carefully determine when to issue a critical event to 
maximize profit. From the data collected by the U.S. Energy Information Administration, CPP is typically combined with a TOU rate, and a critical peak rate can be 3-10 times the off-peak rate [9]. Figure 2 illustrates the residential CPP provided by the Wisconsin Public Service (WPS), which provides electricity and gas in northeast and central Wisconsin [28].

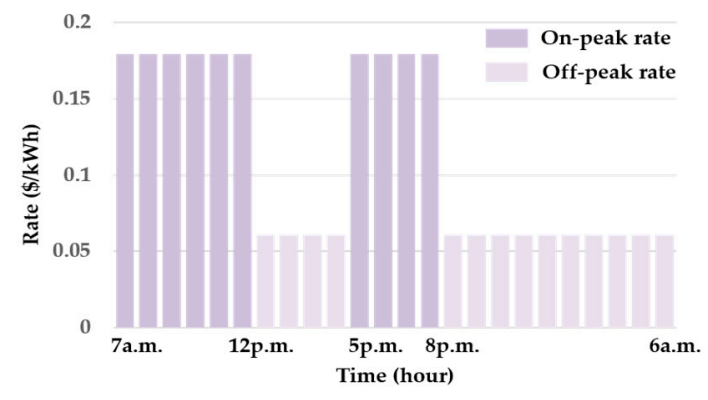

(a)

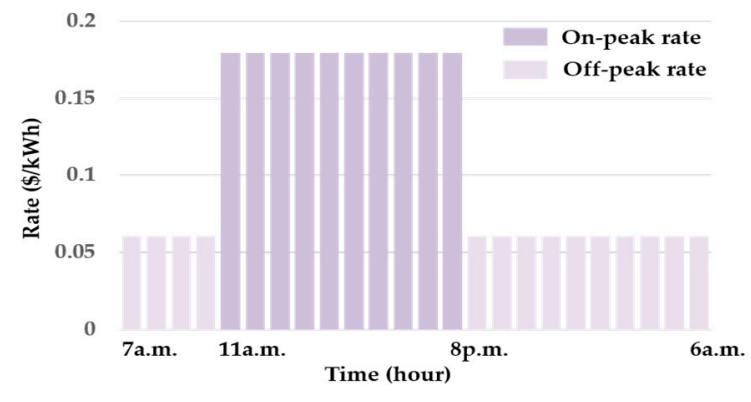

(b)

Figure 2. Practical example of residential critical peak pricing implemented by the Wisconsin Public Service: (a) Winter and (b) summer.

This example of CPP is also combined with a general TOU structure, in which on-peak and off-peak hours vary with season and day of the week [9]. For example, in winter season, on-peak hours are 7 a.m. -12 p.m. and 5 a.m.-8 p.m., from Monday to Friday, except holidays. As shown in Table 1, the on-peak rate, off-peak-rate, and critical peak rate are $0.17933 \$ / \mathrm{kWh}, 0.0607 \$ / \mathrm{kWh}$, and $1.002 \$ / \mathrm{kWh}$, respectively. The critical peak rate is nearly 5.8 times higher than the off-peak rate. WPS can trigger $50 \mathrm{~h}$ of critical events per year and events last between $2 \mathrm{~h}$ and $8 \mathrm{~h}$. In addition, customers are notified at least $1 \mathrm{~h}$ in advance.

Table 1. Critical peak pricing rates of Wisconsin Public Service based on time of day.

\begin{tabular}{|c|c|c|c|}
\hline Classification & Sub-Classification & Winter (October-April) & Summer (May-September) \\
\hline \multirow{3}{*}{ On-peak } & Rate & \multirow{2}{*}{\multicolumn{2}{|c|}{$\begin{array}{c}0.17933 \$ / \mathrm{kWh} \\
\text { Monday-Friday, except holidays }\end{array}$}} \\
\hline & \multirow{2}{*}{ Hours } & & \\
\hline & & $\begin{array}{l}7 \text { a.m. }-12 \text { p.m. and } 5 \\
\text { p.m. }-8 \text { p.m. }\end{array}$ & 11 a.m.-8 p.m. \\
\hline \multirow{2}{*}{ Off-peak } & Rate & \multirow{2}{*}{\multicolumn{2}{|c|}{$\begin{array}{l}\text { 0.0607 \$/kWh } \\
\text { All hours not listed as on-peak hours }\end{array}$}} \\
\hline & Hours & & \\
\hline \multirow{2}{*}{ Critical peak } & Rate & \multicolumn{2}{|c|}{$1.0002 \$ / \mathrm{kWh}$} \\
\hline & Hours & \multicolumn{2}{|c|}{ Vary } \\
\hline
\end{tabular}

Another example of residential CPP is provided by Minnesota Power, where critical peak hours are between 12:00 noon and 3:00 p.m. in summer and between 5:00 p.m. and 8:00 p.m. in winter [29]. In other words, retailers only need to determine the day when the critical event is triggered, since critical peak hours are fixed and last for $3 \mathrm{~h}$. In addition, if there is a serious emergency from the Midcontinent Independent System Operator, critical events can be issued at any time and last up to $8 \mathrm{~h}$. Furthermore, the notification of a standard critical event takes place at 8:00 p.m. the day before event day and at least four hours prior to emergency events.

Consequently, CPP has a variety of pricing structures to handle emergencies in the power system and increase the profit of retailers. Therefore, retailers can exploit CPP by considering their own strategy or power market circumstance.

\subsection{Overview of MSSP and RH Method}

MSSP is usually used to solve planning problems such as those relating to transmission networks or transportation planning, handling sequential decisions under uncertainties at different time horizons 
(stages) [30]. In a multi-stage stochastic model, decisions can be made recursively with the gradual realization of uncertainties over time [31]. In this study, the RH method is exploited for numerical simulation of the problem. Figure 3 shows the concept of an RH method for MSSP.
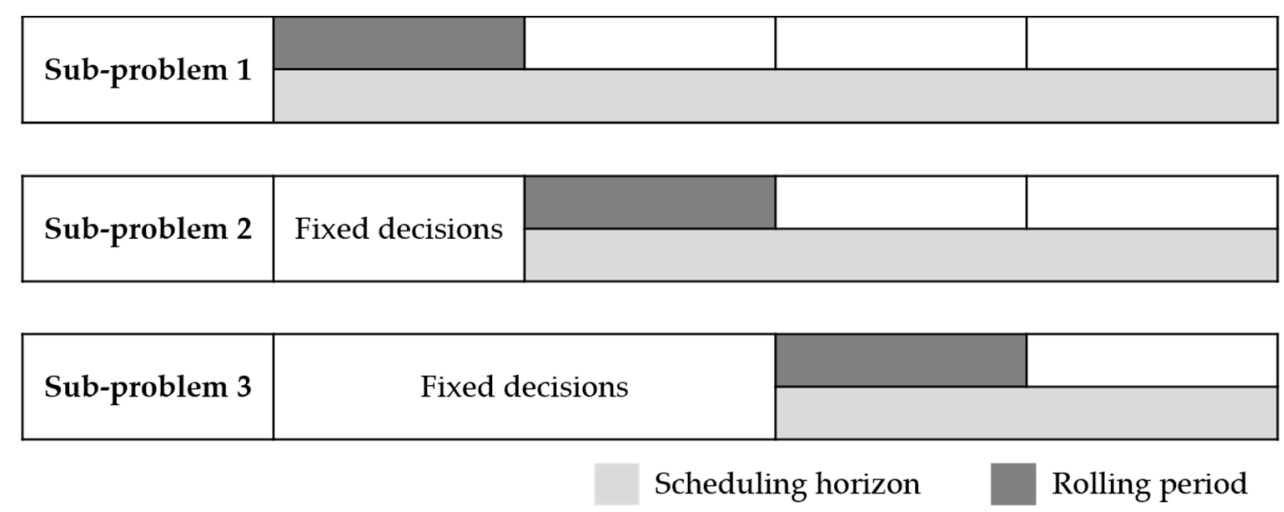

Figure 3. A rolling horizon method for multi-stage stochastic programming.

The RH method is a reactive method that solves sub-problems iteratively by moving the optimization horizon forward with every iteration [32]. As shown in Figure 3, the original problem is decomposed into sub-problems and each sub-problem is solved successively through a scheduling horizon. A rolling period is defined as a period when input parameters associated with uncertainties are updated after the arrival of new information. The rolling period can consist of a multiple number of time steps [33]. Therefore, the forecast data or most recent market information are available to largely reduce uncertainties [34]. In addition, once solutions for a sub-problem are obtained, variables for the previous scheduling horizon are fixed for all subsequent sub-problems. This also helps reduce the complexity of the problem.

\section{Mathematical Formulation}

\subsection{Objective Function}

The objective function of a retailer is to maximize expected profit by optimally bidding in the PXFC market and optimally operating CPP in the retail market. In the PXFC market, a retailer should purchase anticipated demand of customers and the maximum deviation from the anticipated value for dealing with uncertainties. In addition, a retailer sells energy to customers with CPP, which is the retail rate, and decides when to call critical events. Therefore, the profit of a retailer consists of the difference between the revenue from the sale of energy to customers in the retail market and its cost in the PXFC market. In addition, uncertainties such as electricity price, demand, and generation from $\mathrm{PV}$ are represented by multiple scenarios. Specifically, the mathematical formulation of the objective function is as follows:

$$
\begin{aligned}
& \max _{u_{s, t}, E_{s, t}, B D_{s, t}}\left[\sum_{s=1}^{N_{s}} p_{s} \sum_{t=1}^{N_{t}}\left\{u_{s, t} \rho^{C P P} D_{s, t}^{C P P}+\left(1-u_{s, t}\right) \rho^{0} D_{s, t}^{0}\right\}\right. \\
& \quad-\sum_{s=1}^{N_{s}} p_{s} \sum_{t=1}^{N_{t}}\left\{u_{s, t} \rho_{s, t}^{E} E_{s, t}+\left(1-u_{s, t}\right) \rho_{s, t}^{E} E_{s, t}\right\} \\
& \quad-\sum_{s=1}^{N_{s}} p_{s} \sum_{t=1}^{N_{t}}\left\{\left(u_{s, t} \rho_{s, t}^{B D} B D_{s, t}+\left(1-u_{s, t}\right) \rho_{s, t}^{B D} B D_{s, t}\right\}\right. \\
& \left.\quad-\sum_{s=1}^{N_{s}} p_{s} \sum_{t=1}^{N_{t}}\left\{u_{s, t} t_{s, t}^{C P P}+\left(1-u_{s, t}\right) I_{s, t}^{0}\right\}\right]
\end{aligned}
$$

In this study, we assume two rates in CPP to simplify the problem, as in other works [17-19]. The first term in Equation (1) denotes the revenue from selling electricity with CPP to the customers. The next three terms represent purchasing cost of energy, purchasing cost of band capacity, and penalty 
cost in the PXFC market, respectively. $E_{s, t}, B D_{s, t}$, and $u_{s, t}$ are decision variables, which are bidding amount of energy and band capacity in the PXFC market and triggering time of the critical event in the retail market, respectively. The penalty cost function with and without a critical event is defined in Equations (2) and (3). $\Delta E_{s, t}^{C P P}$ and $\Delta E_{s, t}^{0}$ are energy imbalance, respectively, with and without a critical event, which can occur both in the upward and downward directions. Therefore, if the absolute value of the imbalance exceeds the purchased band capacity, a penalty cost is imposed.

$$
\begin{gathered}
I_{s, t}^{C P P}=\max \left(0, \rho^{P}\left(\left|\Delta E_{s, t}^{C P P}\right|-B D_{s, t}\right)\right), \quad \forall s \in N_{s}, \forall t \in N_{t}, \\
I_{s, t}^{0}=\max \left(0, \rho^{P}\left(\left|\Delta E_{s, t}^{0}\right|-B D_{s, t}\right)\right), \quad \forall s \in N_{s}, \forall t \in N_{t} .
\end{gathered}
$$

\subsection{Constraints}

\subsubsection{Demand Reduction with Critical Event}

When a retailer triggers a critical event, demand is reduced in response to the variation in price. In this study, we use the following demand reduction model, as suggested by Park et al. [18].

$$
D_{s, t}^{C P P}=D_{s, t}^{0}\left\{1+\beta\left(\frac{\rho^{C P P}}{\rho^{0}}-1\right)\right\}, \quad \forall s \in N_{s}, \forall t \in N_{t}
$$

where $\beta$ is the price elasticity of the customer; it has a negative value because demand decreases with an increase in price. As described in Equation (4), customers change consumption when the price moves from $\rho^{0}$ to $\rho^{C P P}$. The value of price elasticity experimented in the California Statewide Pricing Pilot ranges from -0.04 to -0.03 under CPP [35].

\subsubsection{Energy Imbalance}

These constraints refer to the energy imbalance with and without a critical event. Energy imbalance occurs when the bidding amount of energy in the PXFC market differs from the real-time energy in scenario $s$ at time $t$, as expressed in Equations (5) and (6). The self-generation PV facility in this study is assumed as a behind-the-meter resource consistent with previous studies [36,37]. Therefore, for each scenario and time, the real-time energy is net load demand defined as the difference between the total customers' demand and the generation of PV resources. Also, for each scenario and time, the real-time energy is the difference between the demand and the generation of PV resources. Theses constraints are described in Equations (7) and (8).

$$
\begin{aligned}
\Delta E_{s, t}^{C P P} & =E_{s, t}-Q_{s, t}^{C P P}, \quad \forall s \in N_{s}, \forall t \in N_{t} \\
\Delta E_{s, t}^{0} & =E_{s, t}-Q_{s, t}^{0}, \quad \forall s \in N_{s}, \forall t \in N_{t} \\
Q_{s, t}^{C P} & =D_{s, t}^{C P}-P_{s, t}, \quad \forall s \in N_{s}, \forall t \in N_{t} \\
Q_{s, t}^{0} & =D_{s, t}^{0}-P_{s, t}, \quad \forall s \in N_{s}, \forall t \in N_{t} .
\end{aligned}
$$

\subsubsection{Critical Event}

The constraints on a critical event consist of the maximum total critical event number, maximum critical event duration, and minimum interval between successive critical events. These constraints are necessary because frequent triggering of a critical event can cause inconvenience of customers and increase their electricity costs. The specific constraints are given as follows: 
Maximum total critical event number $\left(T_{C P P}\right)$

$$
\sum_{t=1}^{N_{t}} u_{s, t} \leq T_{C P P}, \quad \forall s \in N_{s}, \forall t \in N_{t}
$$

Maximum critical event duration $\left(D_{C P P}\right)$

$$
\sum_{t=k}^{k+D_{C P P}} u_{s, t} \leq D_{C P P}, \quad \forall s \in N_{s}, \forall t \in N_{t}, \forall k \in\left\{1,2, \cdots, N_{t}-D_{C P P}\right\}
$$

Minimum interval between successive critical events $\left(S_{C P P}\right)$

$$
\begin{gathered}
\sum_{t=k}^{k+S_{C P P}-1}\left(1-u_{s, t}\right) \geq S_{C P P}\left(u_{s, k-1}-u_{s, k}\right), \quad \forall s \in N_{s}, \forall t \in N_{t}, \forall k \in\left\{1,2, \cdots, N_{t}-S_{C P P}+1\right\}, \\
\sum_{t=k}^{N_{t}}\left(1-u_{s, t}\right) \geq\left(N_{t}-k+1\right)\left(u_{s, k-1}-u_{s, k}\right), \quad \forall s \in N_{s}, \forall t \in N_{t}, \forall k \in\left\{N_{t}-I_{C P P}+2, \cdots, N_{t}\right\} .
\end{gathered}
$$

The total number of critical events is limited to $T_{C P P}$ in each scenario $s$, as described in Equation (9). As for Equation (10), the duration of critical events is limited up to $D_{C P P}$ hours. In addition, the constraint on $S_{C P P}$ is similar to the minimum down time constraint in the unit commitment problem. The constraint in Equation (11) prevents triggering of a critical event for at least $S_{C P P}$ hours, once it is issued. In addition, the constraint in Equation (12) prevents the critical event until the end of the scheduling horizon if it is issued during the final $S_{C P P}-1$ period in the scheduling horizon. In Equations (9)-(12), $u_{s, t}=0$ is assumed for $\forall s \in N_{s}$ and $t \leq 0$.

\subsubsection{Nonanticipativity}

Nonanticipativity constraints in the MSSP model ensure that the decisions, taken at a specific stage, depend only on the information available up to that stage, but are not influenced by future observations.

$$
\begin{aligned}
& u_{s, t}=u_{s \prime, t}, \quad \forall s, s \prime \in N_{s}, s \neq s \prime, \text { for which } \xi_{s,[t]}=\xi_{s \prime,[t]} \\
& E_{s, t}=E_{s \prime, t}, \quad \forall s, s \prime \in N_{s}, s \neq s \prime, \text { for which } \xi_{s,[t]}=\xi_{s \prime,[t]}, \\
& B D_{s, t}=B D_{s \prime, t}, \quad \forall s, s \prime \in N_{s}, s \neq s \prime, \text { for which } \xi_{s,[t]}=\xi_{s \prime,[t]}
\end{aligned}
$$

\subsection{Proposed Algorithm with the RH Method}

The RH method is used to simulate MSSP formulated in this study. Figure 4 shows the algorithm that applies the RH method to MSSP. In the initialization step, given the initial scheduling horizon $\left(N_{t}\right)$ and rolling period $\left(N_{d}\right)$, the total iteration number $\left(i_{\text {tot }}\right)$ is calculated as a value of $N_{t}$ divided by $N_{d}$. In the next step, the uncertain parameters are updated with the new information. For example, in most power markets, electricity prices are publicly announced in day-ahead market on an hourly basis [38]. Therefore, by setting $N_{d}$ as $24 \mathrm{~h}$, the uncertainty of electricity price is largely reduced. Then, in the optimization step, each sub-problem is formulated, deterministically with the updated information on the rolling period and stochastically with the scenarios in the rest of the scheduling horizon after the rolling period [39]. After a sub-problem is solved, we fix the values of $u_{t}, E_{t}$, and $B D_{t}$ during the rolling period. Then, in the modification step, the critical event constraints are revised, since the successive sub-problem should reflect the schedule of the previous critical events. For example, if critical event is triggered at $t=23 \mathrm{~h}$ and $24 \mathrm{~h}$, with $D_{C P P}=2 \mathrm{~h}$ in sub-problem 1 , it cannot be issued at $t=25 \mathrm{~h}$ in sub-problem 2 . This is because the $D_{C P P}$ constraint prevents the issue of a critical event. Therefore, the initial condition of $u_{t}$ related to the critical event constraints in sub-problem 2 will be changed to 
reflect previous $u_{t}$ values in sub-problem 1 . Furthermore, scheduling horizon for the next sub-problem is reduced. Finally, the iteration process terminates when all sub-problems are solved.

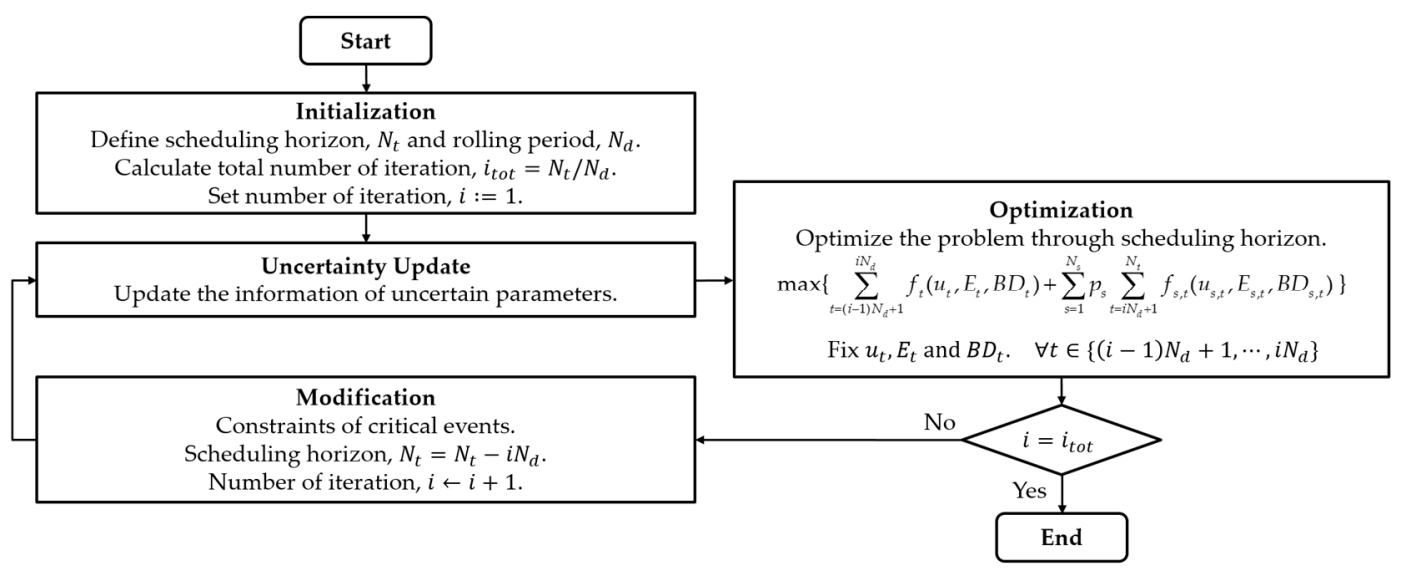

Figure 4. Proposed algorithm with rolling horizon method.

\subsection{Linearization of the MINLP Model}

As shown in Section 3.1, the entire problem is formulated as an MINLP problem. Considering the mathematical complexity of non-linearity, the MINLP problem is solved using a heuristic approach, which, however, does not guarantee a global optimum - this of course depends on the solver [40]. To obtain a global optimum, therefore, we transform the MINLP to an MILP through three linearization steps, as described in the following paragraphs.

The objective function in Equation (1) can be rearranged as shown in Equation (16). For simplicity, the linear terms that do not need to be reformulated are replaced by $L\left(u_{s, t}, E_{s, t}, B D_{s, t}\right)$ function, as given in Equation (17). First, absolute functions in Equation (17) are linearized by introducing positive variables, $\mathrm{Q} P_{s, t}^{C P P}, \mathrm{QN} N_{s, t}^{C P P}, \mathrm{QP}_{s, t}^{0}$, and $\mathrm{QN}_{s, t}^{0}$. Moreover, the constraints related to these positive variables are added to the initial constraints, as shown in Equations (18)-(23).

$$
\begin{aligned}
& \max _{u_{s, t}, E_{s, t}, B D_{s, t s}} \sum_{s=1}^{N_{s}} p_{s} \sum_{t=1}^{N_{t}}\left\{u_{s, t} \rho^{C P P} D_{s, t}^{C P P}+\rho^{0} D_{s, t}^{0}-u_{s, t} \rho^{0} D_{s, t}^{0}-\rho_{s, t}^{E} E_{s, t}-\rho_{s, t}^{B D} B D_{s, t}\right. \\
& -u_{s, t} \max \left(0, \rho^{P}\left(\left|E_{s, t}-Q_{s, t}^{C P P}\right|-B D_{s, t}\right)\right)-\max \left(0, \rho^{P}\left(\left|E_{s, t}-Q_{s, t}^{0}\right|-B D_{s, t}\right)\right), \\
& \left.+u_{s, t} \max \left(0, \rho^{P}\left(\left|E_{s, t}-Q_{s, t}^{0}\right|-B D_{s, t}\right)\right)\right\} \\
& \max _{u_{s, t}, E_{s, t} B D_{s, t}} \sum_{s=1}^{N_{s}} p_{s} \sum_{t=1}^{N_{t}}\left\{L\left(u_{s, t}, E_{s, t}, B D_{s, t}\right)-u_{s, t} \max \left(0, \rho^{P}\left(Q P_{s, t}^{C P P}+Q N_{s, t}^{C P P}-B D_{s, t}\right)\right)\right. \text {, } \\
& \left.-\max \left(0, \rho^{P}\left(Q P_{s, t}^{0}+Q N_{s, t}^{0}-B D_{s, t}\right)\right)+u_{s, t} \max \left(0, \rho^{P}\left(Q P_{s, t}^{0}+Q N_{s, t}^{0}-B D_{s, t}\right)\right)\right\} \\
& E_{s, t}^{C P P}-Q_{s, t}^{C P P}=Q P_{s, t}^{C P P}-Q N_{s, t}^{C P P}, \\
& Q P_{s, t}^{C P P} \geq 0, \\
& Q N_{s, t}^{C P P} \geq 0, \\
& E_{t}^{0}-Q_{s, t}^{0}=Q P_{s, t}^{0}-Q N_{s, t}^{0} \\
& Q P_{s, t}^{0} \geq 0, \\
& Q N_{s, t}^{0} \geq 0,
\end{aligned}
$$

where $\left|E_{s, t}-Q_{s, t}^{C P P}\right|=\mathrm{QP}_{s, t}^{C P P}+\mathrm{QN}_{s, t}^{C P P}$, and $\left|E_{s, t}-Q_{s, t}^{0}\right|=\mathrm{Q} P_{s, t}^{0}+\mathrm{Q} N_{s, t}^{0}$. 
Second, the max functions in Equation (17) are replaced by positive variables, $M_{s, t}^{C P P}$ and $M_{s, t}^{0}$, in Equation (24). In addition, the constraints associated with these positive variables are added in Equations (25)-(28).

$$
\begin{gathered}
\max _{u_{s, t}, E_{s, t}, B D_{s, t}} \sum_{s=1}^{N_{s}} p_{s} \sum_{t=1}^{N_{t}}\left\{L\left(u_{s, t}, E_{s, t}, B D_{s, t}\right)-u_{t} M_{s, t}^{C P P}-M_{s, t}^{0}+u_{t} M_{s, t}^{0}\right\}, \\
M_{s, t}^{C P P} \geq 0, \\
M_{s, t}^{C P P} \geq \rho^{P}\left(Q P_{s, t}^{C P P}+Q N_{s, t}^{C P P}-B D_{s, t}\right), \\
M_{s, t}^{0} \geq 0, \\
M_{s, t}^{0} \geq \rho^{P}\left(Q P_{s, t}^{0}+Q N_{s, t}^{0}-B D_{s, t}\right),
\end{gathered}
$$

where $M_{s, t}^{C P P}=\max \left(0, \rho^{P}\left(\mathrm{QP}_{s, t}^{C P P}+\mathrm{Q} N_{s, t}^{C P P}-B D_{s, t}\right)\right)$, and $M_{s, t}^{0}=\max \left(0, \rho^{P}\left(\mathrm{QP}_{s, t}^{0}+\mathrm{Q} N_{s, t}^{0}-B D_{s, t}\right)\right)$.

Finally, the products of a binary and a continuous variable in Equation (24) are replaced by new positive variables, $z_{s, t}^{C P P}=u_{t} M_{s, t}^{C P P}$, and $z_{s, t}^{0}=u_{t} M_{s, t^{\prime}}^{0}$ as shown in Equation (29). Equations (30)-(37) are constraints related to these positive variables.

$$
\begin{gathered}
\max _{u_{s, t}, E_{s, t}, B D_{s, t}} \sum_{s=1}^{N_{s}} p_{s} \sum_{t=1}^{N_{t}}\left\{L\left(u_{s, t}, E_{s, t}, B D_{s, t}\right)-z_{s, t}^{C P P}-M_{s, t}^{0}+z_{s, t}^{0}\right\}, \\
z_{s, t}^{C P P} \leq A u_{s, t} \\
z_{s, t}^{C P P} \leq M_{s, t}^{C P P}, \\
z_{s, t}^{C P P} \geq M_{s, t}^{C P P}-\left(1-u_{s, t}\right) A, \\
z_{s, t}^{C P P} \geq 0 \\
z_{s, t}^{0} \leq A u_{s, t} \\
z_{s, t}^{0} \leq M_{s, t}^{0} \\
z_{s, t}^{0} \geq M_{s, t}^{0}-\left(1-u_{s, t}\right) A \\
z_{s, t}^{0} \geq 0 .
\end{gathered}
$$

After returning the $L\left(u_{s, t}, E_{s, t}, B D_{s, t}\right)$ function back to the original terms, the final objective function is linearized as shown in Equation (38), and the associated constraints are Equations (4), (7)-(15), (18)-(23), (25)-(28), and (30)-(37). Thus, the initial MINLP problem is reformulated as an MILP.

$$
\max _{u_{s, t} E_{s, t}, B D_{s, t}} \sum_{s=1}^{N_{s}} p_{s} \sum_{t=1}^{N_{t}}\left\{u_{s, t} \rho^{C P P} D_{s, t}^{C P P}+\rho^{0} D_{s, t}^{0}-u_{s, t} \rho^{0} D_{s, t}^{0}-\rho_{s, t}^{E} E_{s, t}-\rho_{s, t}^{B D} B D_{s, t}-z_{s, t}^{C P P}-M_{s, t}^{0}+z_{s, t}^{0}\right\}
$$

\section{Numerical Simulation}

In the simulation, the expected profit of a retailer for a month, $N_{t}=744 \mathrm{~h}$, is optimized by the multi-stage stochastic model proposed in this study. In addition, uncertainty parameters are updated every day on an hourly basis, and therefore, $N_{d}=24 \mathrm{~h}$. Regarding the customer's responsiveness, $\beta$ is assumed to be -0.03 ; other simulation conditions are provided in Table 2.

Uncertainties of demand and PV generation are considered based on the forecast errors and each probability distribution function of forecast error is modeled as an independent normal distribution [41-47]. In each normal distribution, means are set equal to the forecasted values 
and the standard deviations are a specific percentage of the mean value. For the forecasted values of demand and PV generation, day-ahead predicted demand data scaled as $0.5 \%$ of the total demand of PJM in July 2017 [48] and forecasted PV generation data scaled as $5 \%$ of the total installed capacity of Belgium in July 2017 [49] are used, respectively. The standard deviations are 3\% and 10\% of the means, respectively [41]. In addition, day-ahead locational marginal prices obtained from PJM in July 2017 are set as the forecasted values of both energy and band prices [48]. Uncertainty of price is derived by forecast errors of demand and PV generation weighted by Pearson correlation coefficient, respectively, and also the randomness of price itself is added as expressed in Equation (39).

$$
X_{P}^{t}=P_{t}\left(1+\frac{\left(X_{D}^{t}-D_{t}\right)}{D_{t}} \operatorname{corr}_{D, P}+\frac{\left(X_{P V}^{t}-P V_{t}\right)}{P V_{t}} \operatorname{corr}_{P V, P}\right)+X_{r}^{t} .
$$

Based on the probability distribution, 1000 scenarios are generated using the Monte Carlo method with even probability. To reduce computational burden, 1000 original scenarios are reduced to 10 through the backward scenario reduction algorithm, the Kantorovich distance method [50]. One of ten representative scenarios associated with each uncertain parameter is depicted in Figure 5 and each scenario probability is listed in Table 3.

Table 2. Input data used in simulation.

\begin{tabular}{cccc}
\hline Input Data & $\boldsymbol{\rho}_{0}$ & $\rho_{c p p}$ & $\rho_{p}$ \\
\hline Price $(\$ / \mathrm{MWh})$ & 40 & 120 & 150 \\
\hline Input Data & $\boldsymbol{T}_{c p p}$ & $\boldsymbol{D}_{c p p}$ & $\boldsymbol{I}_{c p p}$ \\
\hline Constraints of critical event $(\mathrm{h})$ & 10 & 3 & 12 \\
\hline
\end{tabular}

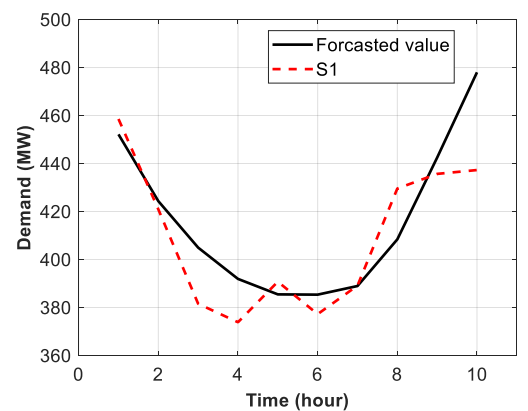

(a)

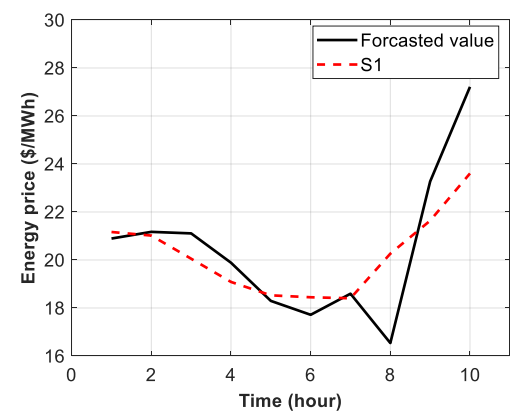

(c)

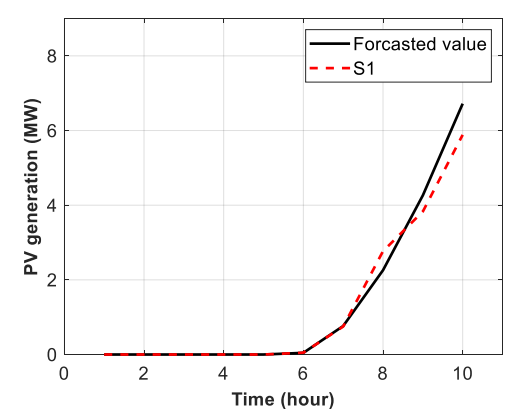

(b)

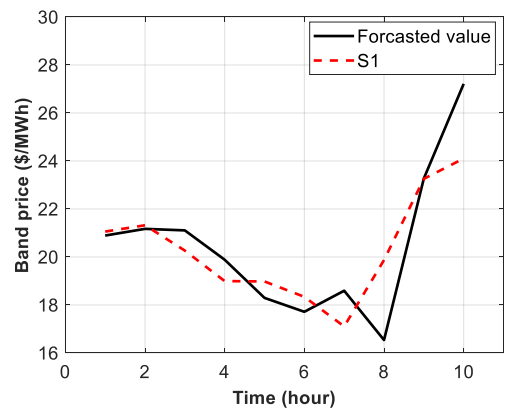

(d)

Figure 5. One of ten representative scenarios and mean values of each distribution for $48 \mathrm{~h}(t=49-$ 96 h): (a) Demand; (b) photovoltaic generation; (c) energy price; and (d) band price.

Furthermore, we assume that some demand peaks that were initially unpredicted emerge over time. These demand peak values are presented in Table 4. Moreover, as explained in Section 3.3, electricity prices are updated daily based on the price announced in the day-ahead PXFC market. 
Table 3. Probability of ten representative scenarios.

\begin{tabular}{ccccccccccc}
\hline Scenario & S1 & S2 & S3 & S4 & S5 & S6 & S7 & S8 & S9 & S10 \\
\hline Probability & 0.064 & 0.083 & 0.116 & 0.082 & 0.102 & 0.237 & 0.075 & 0.059 & 0.06 & 0.122 \\
\hline
\end{tabular}

Table 4. Updated demand peak values.

\begin{tabular}{cccc}
\hline Time (h) & $\mathbf{2 5 5}$ & $\mathbf{2 5 6}$ & $\mathbf{2 5 7}$ \\
\hline Demand (MW) & 890.55 & 890.77 & 907.37 \\
\hline
\end{tabular}

To maximize profit, a retailer optimizes bidding amount of energy and band capacity in the PXFC market and when issuing critical events in the retail market. The resulting optimal bidding amount of hourly energy and band capacity are represented by the solid line and dotted line, respectively, in Figure 6. In addition, the positive and negative violations that exceed the band capacity are depicted in Figure 7. A penalty price is imposed on the amount of violation.

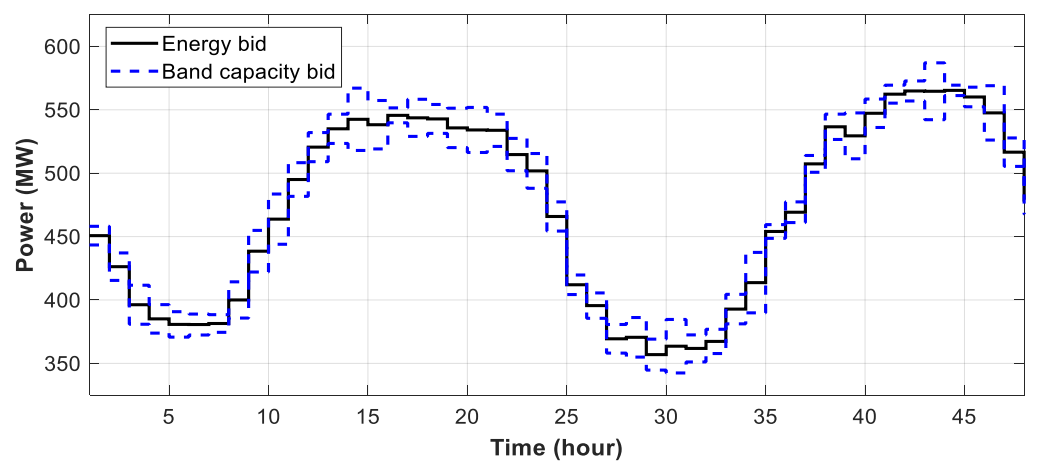

Figure 6. Optimal bidding amount of energy and band capacity for $48 \mathrm{~h}$.

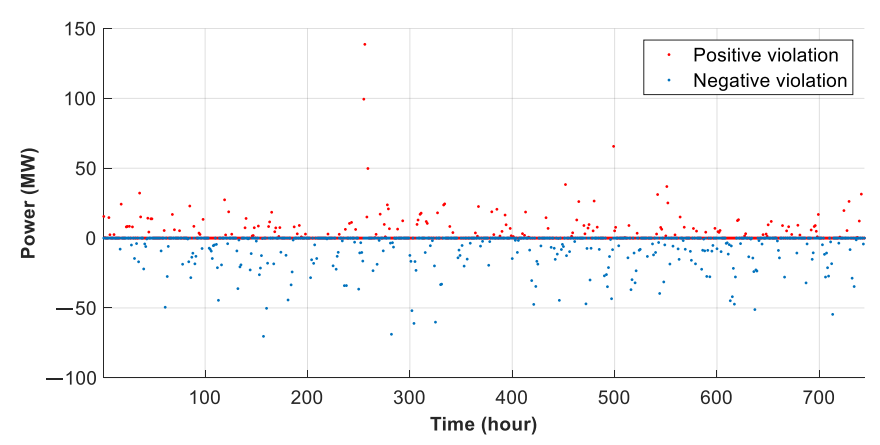

Figure 7. Positive and negative violations.

\subsection{Comparison Between the Mean-Value Deterministic Model and Multi-Stage Stochastic Model}

This section analyzes the optimization results of the mean-value deterministic model and multi-stage stochastic model to validate the effectiveness of the proposed model. First, profits of the retailer calculated for one month in these two models are compared in Table 5. Total profit is greater by $2.45 \%$, revenue is higher, and all costs are lower in the multi-stage model than the mean-value deterministic model.

Table 6 shows the optimal critical event schedule of each model. The intuitive explanation for the notification of critical events at time periods 255, 256, and 257 in the multi-stage model is that the optimal schedule reflects the re-predicted demand peaks. Analytically, a shift in critical event time can be explained by the profit index (PI), defined in Park et al. [18]. The PI is an additional profit for the retailer when a critical event is triggered for each time period $t$. Table 7 lists the PI results for different 
critical event schedules in each model. The PIs are higher for time periods 255, 256, and 475 than for time periods are 281, 282, and 472 in both models. In other words, periodically updating market information with the most recent data can trigger critical events more accurately, and maximize profit, with the multi-stage stochastic model compared to the mean-value deterministic model.

Table 5. Operation results of mean-value deterministic model and multi-stage stochastic model.

\begin{tabular}{cccccc}
\hline \multirow{2}{*}{ Model } & \multirow{2}{*}{ Profit (\$) } & \multirow{2}{*}{ Revenue (\$) } & \multicolumn{3}{c}{ Costs (\$) } \\
\cline { 4 - 6 } & & & Purchasing Energy & Purchasing Band Capacity & Penalty \\
\hline Mean-value & $2,770,585$ & $15,848,124$ & $11,678,390$ & 507,935 & 891,214 \\
deterministic & $2,838,581$ & $15,874,009$ & $11,672,411$ & 509,280 & 853,737 \\
\hline Multi-stage stochastic & 2 &
\end{tabular}

Table 6. Optimal critical event schedule in each model.

\begin{tabular}{cc}
\hline Model & Optimal Critical Event Schedule \\
\hline Mean-value deterministic & $257,281,282,305,473,474,475,496,497,498$ \\
Multi-stage stochastic & $255,256,257,305,472,473,474,496,497,498$ \\
\hline
\end{tabular}

Table 7. Profit index (PI) at different event schedule in each model

\begin{tabular}{cccc}
\hline Model & $\mathbf{P I}_{255}(\$)$ & $\mathbf{P I}_{256}(\$)$ & $\mathbf{P I}_{281}(\$)$ \\
\hline $\begin{array}{c}\text { Mean-value } \\
\text { deterministic }\end{array}$ & 75,706 & 79,545 & 58,384 \\
Multi-stage stochastic & 75,706 & 79,545 & 48,005 \\
\hline Model & $\mathbf{P I}_{282}(\$)$ & $\mathbf{P I}_{472}(\$)$ & $\mathbf{P I}_{475}(\$)$ \\
\hline $\begin{array}{c}\text { Mean-value } \\
\text { deterministic }\end{array}$ & 45,830 & 50,351 & 64,887 \\
Multi-stage stochastic & 45,830 & 50,351 & 54,320 \\
\hline
\end{tabular}

\subsection{Impact of Input Parameters Change}

This section investigates the strategy and profit of a retailer with the variation of four input parameters. First, as shown in Figure 8a, the profit of the retailer monotonically decreases with an increase in the absolute value of price elasticity of demand $(|\beta|)$. An increase in $|\beta|$ means that demand further reduces in response to a variation in price, as expressed in Equation (4). Table 8 summarizes the total demand reduction for different price elasticities of the demand. The decrease in profit can be explained in relation to the demand reduction as follows. It is because sales revenue, which applies a high peak rate to the remaining demand when a critical event is issued, is greater than the overall cost savings in the PXFC market due to demand reduction. Consequently, the profit of the retailer decreases as demand is further reduced.

Table 8. Total demand reduction for different price elasticities of customer.

\begin{tabular}{ccccccc}
\hline $\boldsymbol{\beta}$ & $\mathbf{- 0 . 0 1}$ & $\mathbf{- 0 . 0 2}$ & $\mathbf{- 0 . 0 3}$ & $\mathbf{- 0 . 0 4}$ & $\mathbf{- 0 . 0 5}$ & $\mathbf{- 0 . 0 6}$ \\
\hline Total demand reduction (MW) & 157 & 314 & 471 & 628 & 785 & 942 \\
\hline
\end{tabular}

Second, as shown in Figure 8b, the profit of the retailer increases as the maximum critical event duration $\left(D_{C P P}\right)$ increases. This is because the longer a critical event lasts after its triggering, the more relaxed the critical event constraint is. In Figure $8 b$, the retailer's profit appears to be the same when $D_{C P P}$ is $3 \mathrm{~h}$ and $4 \mathrm{~h}$. However, precisely when $D_{C P P}$ is $4 \mathrm{~h}$ to $5 \mathrm{~h}$, the profit increases slightly and the optimal critical event schedule changes, as shown in Table 9. The optimal critical event schedule for different values of $D_{C P P}$ is also summarized in Table 9, with successive critical events separated by a 
slash. Eventually, the profit converges when $D_{C P P}$ exceeds $5 \mathrm{~h}$ because there is no need to maintain critical event.

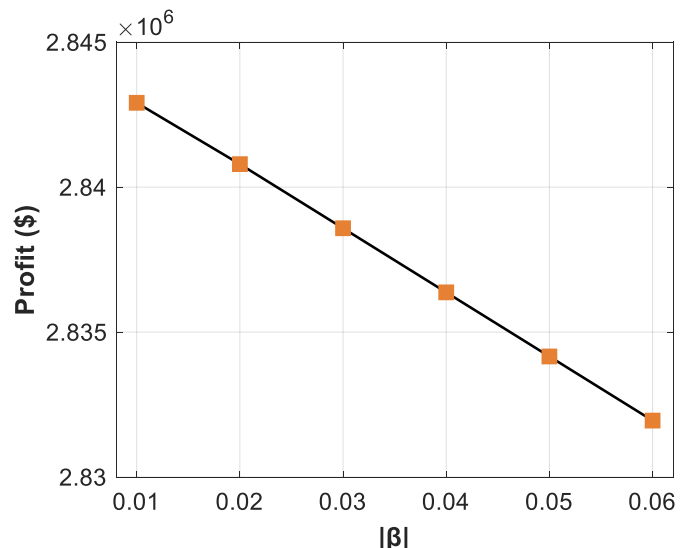

(a)

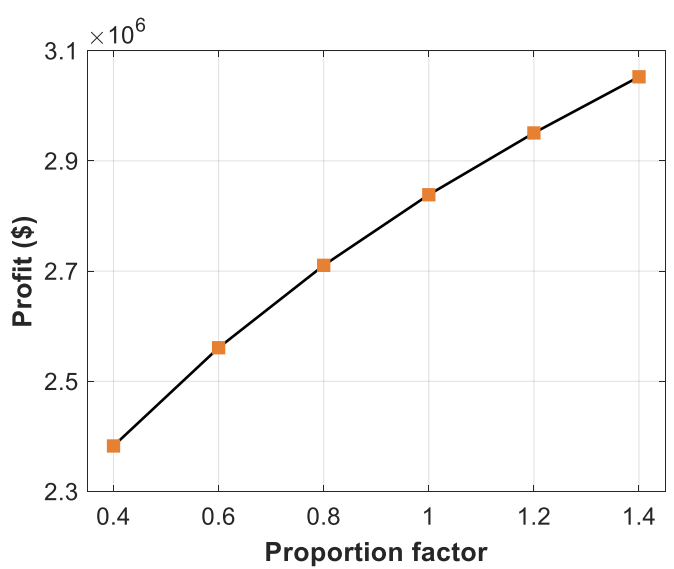

(c)

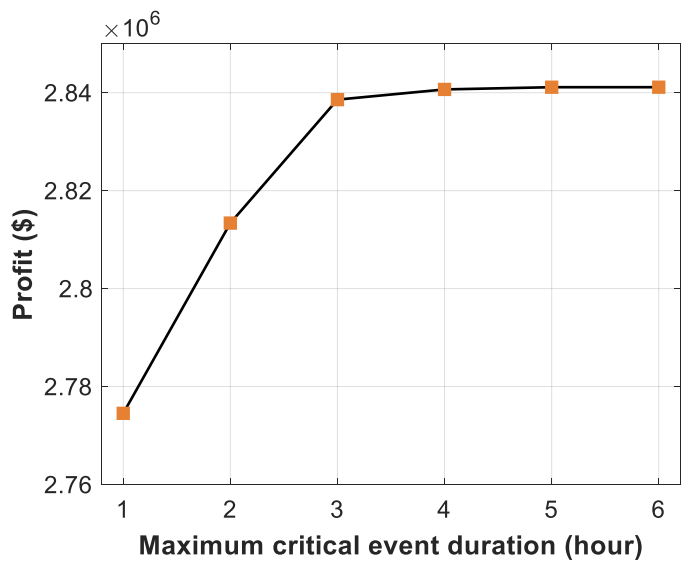

(b)

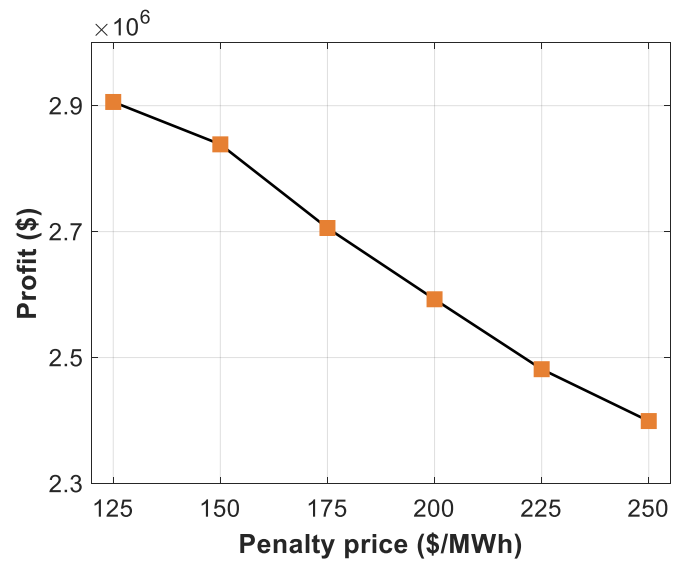

(d)

Figure 8. Impact of each input parameter on the profit of the retailer: (a) Price elasticity of demand;

(b) maximum critical event duration; (c) photovoltaic proportion factor; and (d) penalty price.

Third, we analyze the retailer's profit by introducing a PV proportion factor (PF) to adjust the capacity of the self-generation PV facility. In the case of a reference PV capacity, PF is set as 1.0. As shown in Figure 8c, an increase in the PF leads to a monotonic increase in the retailer's profit. This is because the amount of energy that should be purchased in the PXFC market decreases as PF increases, as seen in Figure 9. However, with the increasing fluctuation in PV generation as the PF rises, the retailer purchases more band capacity to prevent an extreme increase in penalty costs. In other words, when the probability of exceeding the band capacity increases, the retailer will establish a more conservative bidding strategy. Figure 10 illustrates optimal purchases of energy and band capacities for different PFs.

Table 9. Optimal critical event schedule and retailer's profit for different values of $D_{C P P}$.

\begin{tabular}{ccc}
\hline $\boldsymbol{D}_{c p p}$ & Optimal Critical Event Schedule & Profit (\$) \\
\hline 1 & $65 / 257 / 282 / 305 / 425 / 450 / 474 / 497 / 521 / 570$ & $2,774,535$ \\
2 & $256,257 / 281,282 / 304,305 / 473,474 / 497,498$ & $2,813,374$ \\
3 & $255,256,257 / 305 / 472,473,474 / 496,497,498$ & $2,838,581$ \\
4 & $255,256,257 / 471,472,473,474 / 496,497,498$ & $2,840,666$ \\
5 & $255,256,257 / 471,472,473,474,475 / 497,498$ & $2,841,121$ \\
6 & $255,256,257 / 471,472,473,474,475 / 497,498$ & $2,841,121$ \\
\hline
\end{tabular}




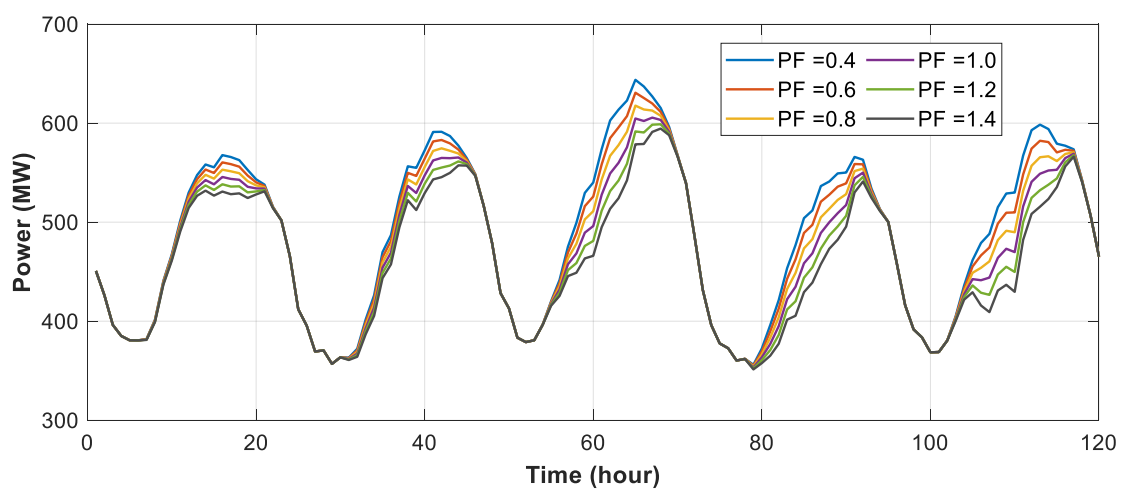

Figure 9. Amount of energy purchased for $120 \mathrm{~h}$ with different proportion factors. PF, proportion factor.

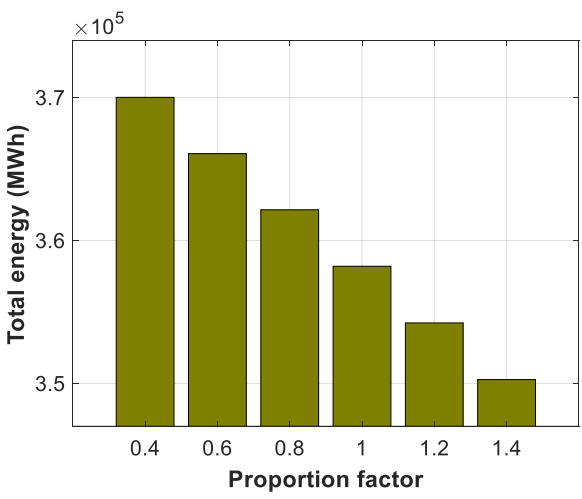

(a)

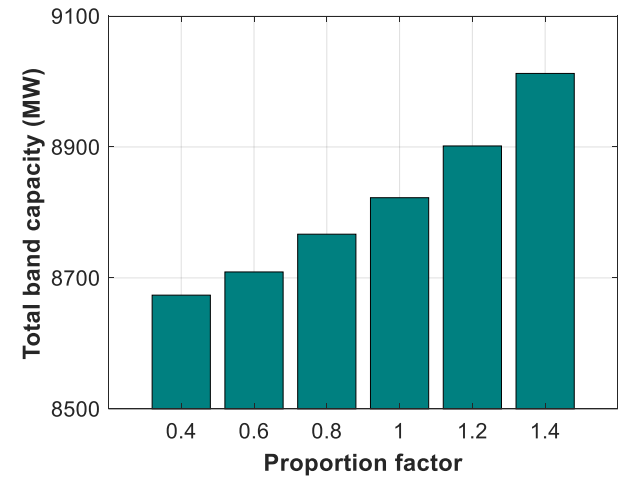

(b)

Figure 10. Total amount of energy and band capacity purchased for different proportion factors. (a) Energy and (b) band capacity.

Finally, a higher penalty price leads to a monotonic decrease in the retailer's profit, as shown in Figure $8 \mathrm{~d}$. Similar to the case of $\mathrm{PF}$, if the penalty price increases, the retailer purchases band capacity more conservatively to prevent a sharp increase in penalty costs. From Table 10, we can see that if the penalty price increases by 2 times, from 125 to $250 \$ / \mathrm{MWh}$, retailer purchases 1.62 times more band capacity and the penalty cost increases by 1.21 times.

Table 10. Total purchased band capacity and penalty cost for different penalty prices.

\begin{tabular}{ccc}
\hline Penalty Price (\$/MWh) & Band Capacity (MW) & Penalty Cost (\$) \\
\hline 125 & 7531 & 872,474 \\
150 & 8822 & 853,737 \\
175 & 9884 & 913,932 \\
200 & 10,797 & 965,932 \\
225 & 11,565 & $1,021,864$ \\
250 & 12,204 & $1,059,206$ \\
\hline
\end{tabular}

\subsection{Sensitivity Analysis}

In this section, we conduct a sensitivity analysis to assess the impact of each uncertain parameter on the retailer's profit. First, we define an uncertainty factor (UF) that scales the standard deviation of each uncertain parameter so that the degree of uncertainty can be changed. UF of price, demand and $P V$ generation are represented as $U F_{P}, U F_{D}$, and $U F_{P V}$, respectively. By Equation (39), $U F_{P}^{t}$, which refers to $U F_{P}$ at time period $t$, can be derived as a function of $U F_{D}$ and $U F_{P V}$ as in Equation (40). To make one representative value over the time period, the average value of $U F_{P}^{t}$ can be obtained from Equation (41). In Table 11, $U F_{P}$ is calculated for each pair of $U F_{D}$ and $U F_{P V}$ and it can be observed that 
the $U F_{D}$ has a greater impact on $U F_{P}$ than $U F_{P V}$. Profit by changing UF for uncertain parameters of demand and PV generation is shown in Figure 11 and Table 12. Since the PV generation is extremely small compared to demand, as seen in Figure 11, the increase in the $U F_{P V}$ does not have a significant impact on the retailer's profit. There are even intervals where the retailer's profit increases as the $U F_{P V}$ increases. This is because the retailer revises the optimal schedule by reflecting the increased uncertainties. Thus, the retailer maintains a consistent profit level. In contrast, the increased $U F_{D}$ results in a significant decrease in the retailer's profit, as shown in Table 12. In other words, in this case, a shift in the optimal critical event schedule does not prevent profit reduction.

$$
\begin{aligned}
& U F_{P}^{t}=\sqrt{\frac{\sigma_{r}^{2}+\left(\frac{P_{t} \text { corr }_{D, P \sigma_{D}}}{D_{t}} U F_{D}\right)^{2}+\left(\frac{P_{t} \operatorname{corr}_{P V, P \sigma_{P V}}}{P V_{t}} U F_{P V}\right)^{2}}{\sigma_{r}^{2}+\left(\frac{P_{t} c o r r_{D, P} \sigma_{D}}{D_{t}}\right)^{2}+\left(\frac{P_{t} \operatorname{corr}_{P V, P} \sigma_{P V}}{P V_{t}}\right)^{2}} .}
\end{aligned}
$$

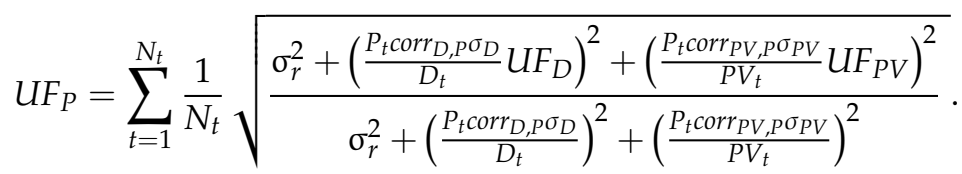

Table 11. Uncertainty factor (UF) of price.

\begin{tabular}{|c|c|c|c|c|c|c|}
\hline \multirow{2}{*}{\multicolumn{2}{|c|}{$U F_{P}$}} & \multicolumn{5}{|c|}{$U F_{D}$} \\
\hline & & 0.6 & 0.8 & 1.0 & 1.2 & 1.4 \\
\hline \multirow{5}{*}{$U F_{P V}$} & 0.6 & 0.6262 & 0.7410 & 0.8600 & 0.9813 & 1.1039 \\
\hline & 0.8 & 0.7017 & 0.8113 & 0.9267 & 1.0455 & 1.1662 \\
\hline & 1.0 & 0.7849 & 0.8887 & 1.0000 & 1.1156 & 1.2340 \\
\hline & 1.2 & 0.8737 & 0.9717 & 1.0784 & 1.1906 & 1.3063 \\
\hline & 1.4 & 0.9669 & 1.0590 & 1.1611 & 1.2696 & 1.3824 \\
\hline
\end{tabular}

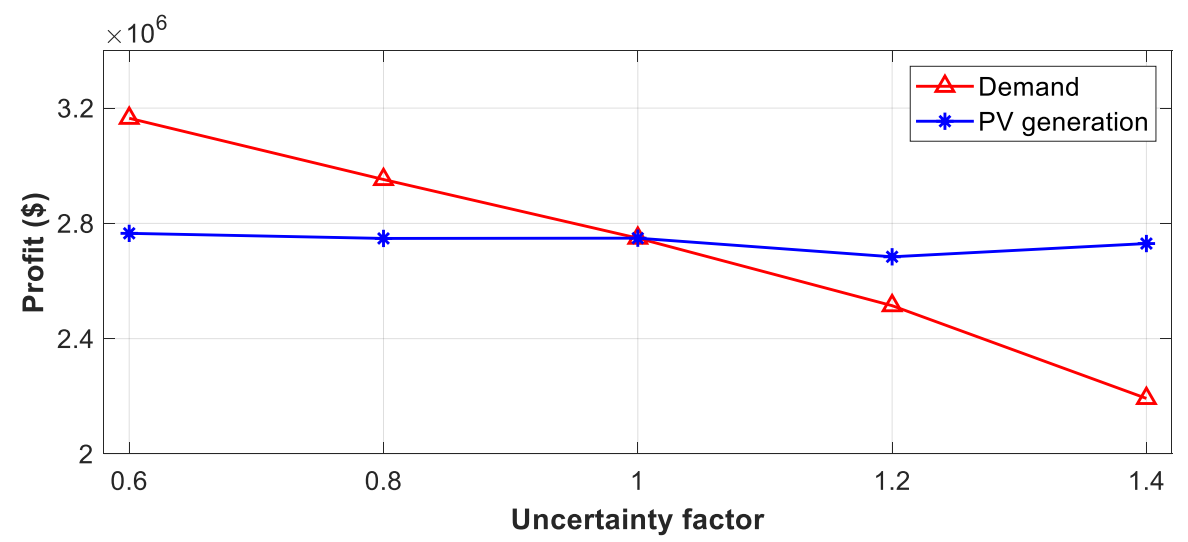

Figure 11. Impact of uncertainty factor on retailer's profit.

Table 12. Profit change for different pair of uncertainty factors (\$).

\begin{tabular}{ccccccc}
\hline \multirow{2}{*}{ Profit (\$) } & \multicolumn{5}{c}{$U F_{\boldsymbol{D}}$} \\
\cline { 3 - 7 } & $\mathbf{0 . 6}$ & $\mathbf{0 . 8}$ & $\mathbf{1 . 0}$ & $\mathbf{1 . 2}$ & $\mathbf{1 . 4}$ \\
\hline \multirow{4}{*}{$U F_{P V}$} & $\mathbf{0 . 6}$ & $3,203,048$ & $2,995,153$ & $2,765,404$ & $2,443,881$ & $2,282,891$ \\
& $\mathbf{0 . 8}$ & $3,198,617$ & $2,987,038$ & $2,747,736$ & $2,447,954$ & $2,288,846$ \\
& $\mathbf{1 . 0}$ & $3,164,769$ & $2,952,281$ & $2,798,589$ & $2,424,483$ & $2,192,705$ \\
& $\mathbf{1 . 2}$ & $3,169,896$ & $2,948,796$ & $2,684,038$ & $2,434,676$ & $2,246,904$ \\
& $\mathbf{1 . 4}$ & $3,157,469$ & $2,933,102$ & $2,729,988$ & $2,446,274$ & $2,235,362$ \\
\hline
\end{tabular}




\subsection{Effect of the Energy Storage System}

In this section, the effect of the energy storage system (ESS) on the proposed optimization problem is investigated. For the ESS operation, a rule-based strategy is applied, in which ESS is charged when the energy price is low, and discharged when the energy price is high, to reduce the purchasing cost of energy in the PXFC market. Parameters of ESS are summarized in Table 13. It is assumed that the number of cycles per day is limited to one and the initial stored energy is $1 \mathrm{MWh}$. Figure 12 illustrates the power of ESS based on the rule-based strategy for $24 \mathrm{~h}$. From the operation result, the retailer's profit increases by $3.22 \%$ with the same optimal critical event schedule compared to the case when ESS is not utilized as shown in Table 14.

Table 13. Parameters of the energy storage system.

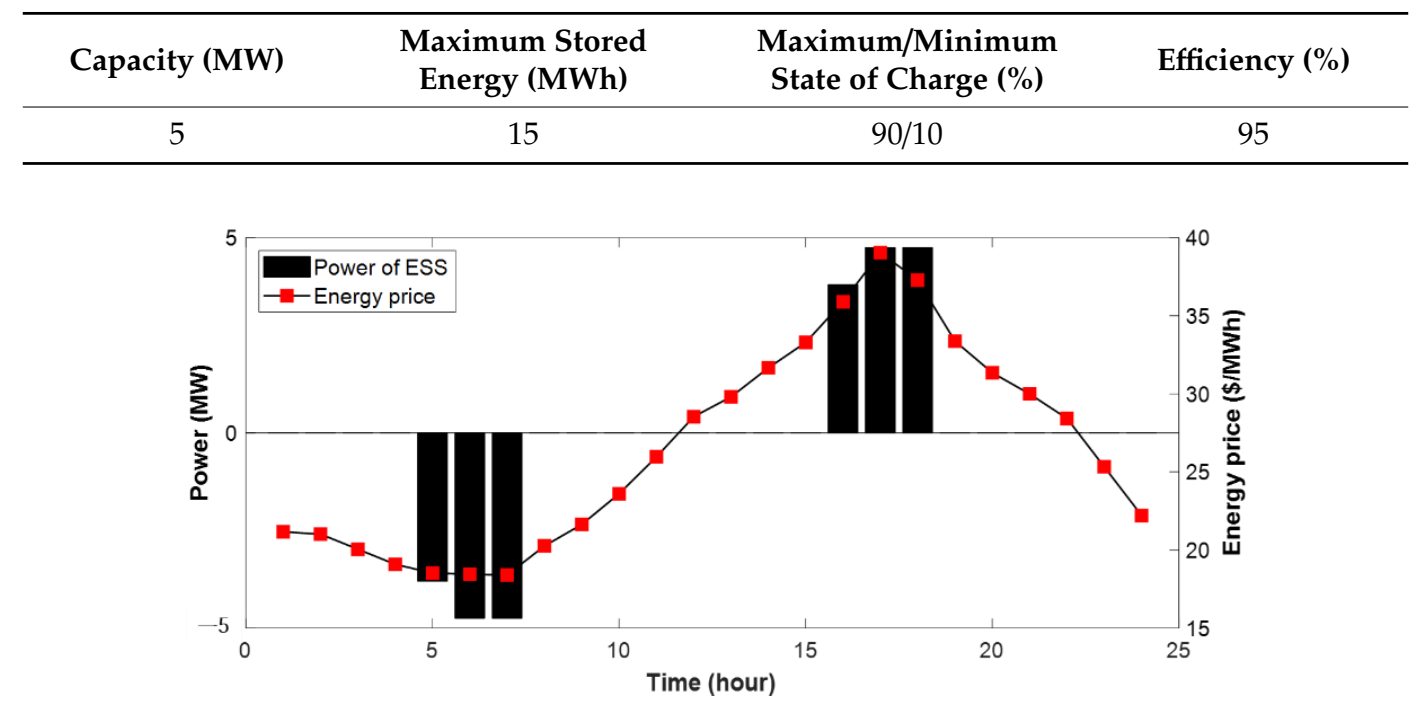

Figure 12. Power of energy storage system based on rule-based strategy.

Table 14. Operation results of utilizing energy storage system.

\begin{tabular}{cc}
\hline Profit (\$) & Optimal Critical Event Schedule \\
\hline $2,930,091$ & $255,256,257,305,472,473,474,496,497,498$ \\
\hline
\end{tabular}

\section{Conclusions}

This paper proposes an optimal CPP operation for a retailer with a self-generation PV facility. The problem is formulated as an MINLP model to optimize both the bidding strategy in the PXFC market and CPP operation in the retail market. In addition, an MSSP model is established for the retailer to address the uncertainties of electricity price, demand, and PV generation. By using the MSSP model, solutions can be determined sequentially with realization of uncertainties. The RH method is used to simulate the problem to change the decisions iteratively. Furthermore, to ensure global optimality, the MINLP is transformed into an MILP through three steps. In a numerical simulation, the proposed multi-stage stochastic model yields higher total profit than the mean-value deterministic model. In addition, we investigate the optimal strategy of the retailer by changing four input parameters: Price elasticity of demand, maximum critical event duration, PV PF, and penalty price. Sensitivity analysis confirms that a retailer's profit is more sensitive to the uncertainty of demand than that of PV generation. Finally, the effect of the energy storage system on the proposed optimization problem is investigated.

However, some challenges still remain for future research, such as accurately modeling the characteristics of residential demands. For example, we can consider the payback phenomenon. If demand is reduced, some of it will be shifted to another time period. It is difficult to stochastically 
model the extent to which or the time when reduced amount of demand will shift. However, as mentioned above, demand uncertainty has the greatest impact on a retailer's profit. Therefore, future studies can consider the payback phenomenon stochastically for a more practical implementation of CPP. Also, as many previous studies have demonstrated that curtailment of energy generation from RESs can obtain an economic benefit, an effect of active control of RESs can be highlighted in the proposed problem as future work. Finally, the same values are employed for energy and band capacity prices in this study. It is because the price difference between the two products may lead to complex strategic behavior of the participants in the PXFC market. Therefore, the proposed method can be extended to cope with the price difference between energy and band capacity in the future study.

Author Contributions: Conceptualization, methodology, software, and writing-original draft preparation, H.Y.S.; investigation, writing-review, editing, and supervision, G.S.L.; conceptualization and validation, Y.T.Y.

Funding: This work was supported by the Human Resources Development Program of Korea Institute of Energy Technology Evaluation and Planning (KETEP) under a grant (No. 20194030202420) funded by the Korean Ministry of Trade, Industry and Energy.

Acknowledgments: This work was supported by Seoul National University Electric Power Research Institute (SEPRI).

Conflicts of Interest: The authors declare no conflicts of interest.

\section{Nomenclature}

$s \quad$ Index of scenario

$N_{S} \quad$ Number of scenarios

$N_{t} \quad$ Scheduling horizon

$\beta \quad$ Price elasticity of customer

$p_{S} \quad$ Probability of scenario $s$

$D_{C P P} \quad$ Maximum critical event duration (h)

$T_{C P P} \quad$ Maximum total critical event number $(\mathrm{h})$

$I_{C P P} \quad$ Minimum interval between successive critical events (h)

$\rho^{0} \quad$ Base rate in critical peak pricing $(\$ / \mathrm{MWh})$

$\rho^{C P P} \quad$ Peak rate in critical peak pricing $(\$ / \mathrm{MWh})$

$\rho^{P} \quad$ Penalty price $(\$ / \mathrm{MWh})$

$\rho_{s, t}^{E} \quad$ Energy price in PXFC market at time $t$ in scenario $s(\$ / \mathrm{MWh})$

$\rho_{s, t}^{B D} \quad$ Band price in PXFC market at time $t$ in scenario $s(\$ / M W h)$

$Q_{s, t}^{0} \quad$ Amount of real-time energy without critical event in scenario $s$ at time $t$

$Q_{s, t}^{C P P} \quad$ Amount of real-time energy with critical event in scenario $s$ at time $t$

$D_{s, t}^{0} \quad$ Demand without a critical event in scenario $s$ at time $t$

$D_{s, t}^{C P P} \quad$ Demand with a critical event in scenario $s$ at time $t$

$P_{s, t} \quad$ Photovoltaic generation in scenario $s$ at time $t$

$\Delta E_{s, t}^{0} \quad$ Imbalance without critical event in scenario $s$ at time $t$

$\triangle E_{s, t}^{C P P} \quad$ Imbalance with critical event in scenario $s$ at time $t$

$I_{S, t}^{0}$

$I_{s, t} I_{s, t} P$

$u_{s, t}$

Penalty cost without a critical event in scenario $s$ at time $t$

Penalty cost with a critical event in scenario $s$ at time $t$

Critical event decision binary variable in scenario $s$ at time $t$

$B D_{s, t} \quad$ Decision variable determining band capacity in scenario $s$ at time $t$

$E_{s, t} \quad$ Decision variable determining energy in scenario $s$ at time $t$

$\xi_{s,[t]} \quad$ History of the stochastic process of uncertain parameters up to time period $\mathrm{t}$

$A \quad$ Large enough positive constant

$\mathrm{Q} P{ }_{s, t}^{C P P} \quad$ Positive variable for linearization

$\mathrm{Q} N_{s, t}^{C P P} \quad$ Positive variable for linearization

$\mathrm{QP}_{s, t}^{0, t} \quad$ Positive variable for linearization

$\mathrm{QN}_{s, t}^{0} \quad$ Positive variable for linearization 


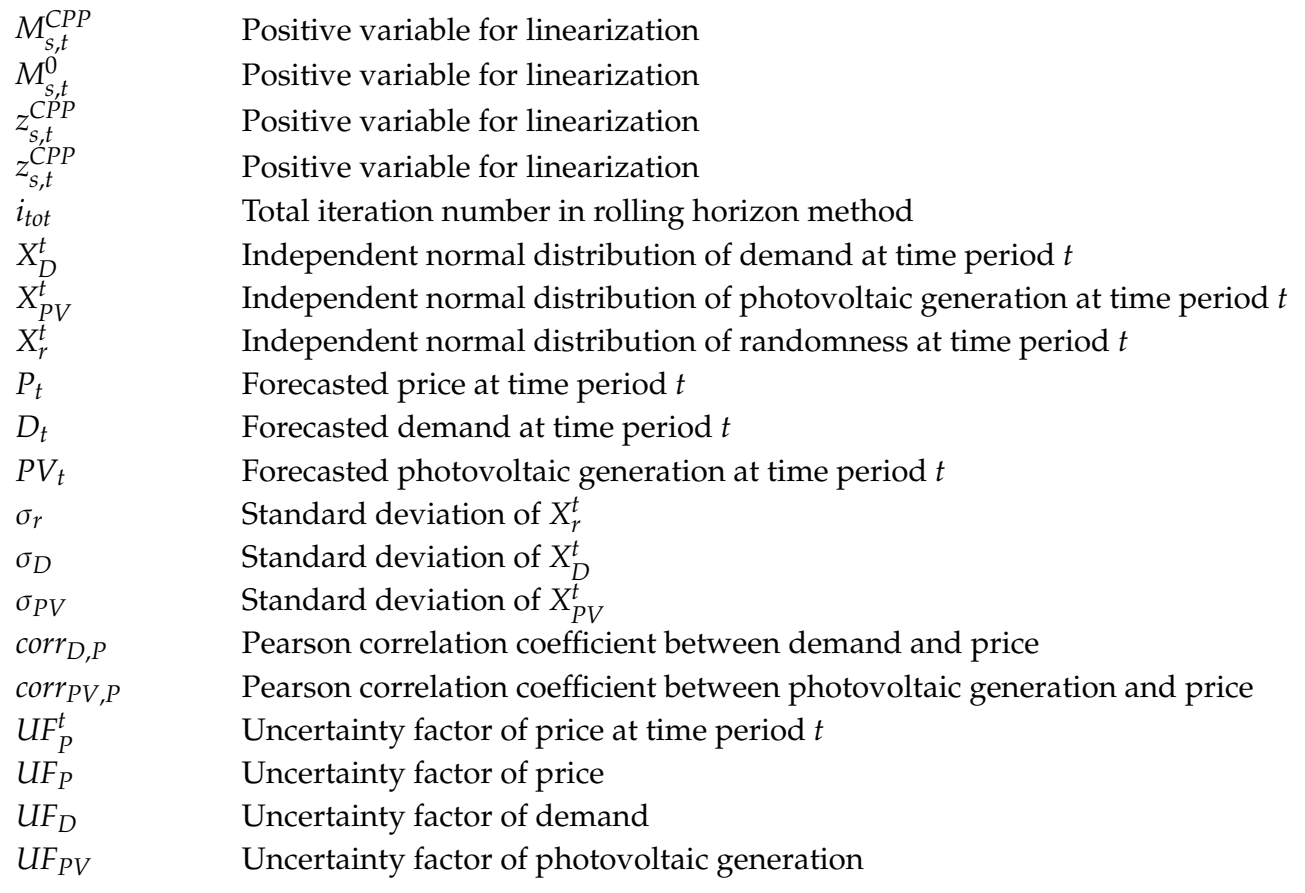

\section{Acronyms}

$\begin{array}{ll}\text { RESs } & \text { Renewable energy sources } \\ \text { CPP } & \text { Critical peak pricing } \\ \text { PBP } & \text { Price-based program } \\ \text { MSSP } & \text { Multi-stage stochastic programming } \\ \text { PV } & \text { Photovoltaic } \\ \text { RH } & \text { Rolling horizon } \\ \text { MINLP } & \text { Mixed integer non-linear programming } \\ \text { MILP } & \text { Mixed integer linear programming } \\ \text { IBP } & \text { Incentive-based program } \\ \text { CBL } & \text { Customer baseline load } \\ \text { RTP } & \text { Real-time pricing } \\ \text { TOU } & \text { Time of use } \\ \text { PXFC } & \text { Power exchange for frequency control } \\ \text { WPS } & \text { Wisconsin Public Service } \\ \text { PF } & \text { Proportion factor } \\ \text { UF } & \text { Uncertainty factor }\end{array}$

\section{References}

1. Joskow, P.L. Challenges for Wholesale Electricity Markets with Intermittent Renewable Generation at Scale: The US Experience. Oxf. Rev. Econ. Policy 2019, 35, 291-331. [CrossRef]

2. Dutta, G.; Mitra, K.A. Literature Review on Dynamic Pricing of Electricity. J. Oper. Res. Soc. 2017, 68, 1131-1145. [CrossRef]

3. Bartelj, L.; Gubina, A.F.; Paravan, D.; Golob, R. Risk Management in the Retail Electricity Market: The Retailer's Perspective. In Proceedings of the IEEE PES General Meeting, Providence, RI, USA, 25-29 July 2010.

4. Golmohamadi, H.; Keypour, R. Retail Energy Management in Electricity Markets: Structure, Challenges and Economic Aspects- A Review. Technol. Econ. Smart Grids Sustain. Energy 2017, 2. [CrossRef]

5. Albadi, M.H.; El-Saadany, E.F. A Summary of Demand Response in Electricity Markets. Electr. Power Syst. Res. 2008, 78, 1989-1996. [CrossRef]

6. Ho, T.; Shinkuma, S.; Shimada, K. The Effects of Dynamic Pricing of Electric Power on Consumer Behavior: A Propensity Score Analysis for Empirical Study on Nushima Island, Japan. Energies 2018, 11, 2175. [CrossRef] 
7. Borenstein, S.; Jaske, M.; Rosenfeld, A. Dynamic Pricing, Advanced Metering, and Demand Response in Electricity Markets; Technical Report, CSEM WP 105; UCEI: Berkeley, CA, USA, 2002.

8. Jessoe, K.; Rapson, D. Commercial and Industrial Demand Response under Mandatory Time-of-Use Electricity Pricing. J. Ind. Econ. 2015, 63, 397-421. [CrossRef]

9. IEA. Form EIA-861 Annual Electric Power Industry Report Instructions; U.S. Energy Information Administration: Washington, DC, USA, 2018.

10. Hu, Z.; Kim, J.; Wang, J.; Byrne, J. Review of Dynamic Pricing Programs in the U.S. and Europe: Status Quo and Policy Recommendations. Renew. Sustain. Energy Rev. 2015, 42, 743-751. [CrossRef]

11. Herter, K.; McAuliffe, P.; Rosenfeld, A. Observed Temperature Effects on Hourly Residential Electric Load Reduction in Response to an Experimental Critical Peak Pricing Tariff; Lawrence Berkeley National Laboratory: Berkeley, CA, USA, 2005.

12. Herter, K. Residential Implementation of Critical-Peak Pricing of Electricity. Energy Policy 2007, 35, $2121-2130$. [CrossRef]

13. Herter, K.; Wayland, S. Residential Response to Critical-Peak Pricing of Electricity: California Evidence. Energy 2010, 35, 1561-1567. [CrossRef]

14. Herter, K.; McAuliffe, P.; Rosenfeld, A. An Exploratory Analysis of California Residential Customer Response to Critical Peak Pricing of Electricity. Energy 2007, 32, 25-34. [CrossRef]

15. Wolak, A. An Experimental Comparison of Critical Peak and Hourly Pricing: The PowerCentsDC Program; Working Paper; Stanford University: Stanford, CA, USA, 2010.

16. Fenrick, S.A.; Getachew, L.; Ivanov, C.; Smith, J. Demand Impact of a Critical Peak Pricing Program: Opt-in and Opt-out Options, Green Attitudes and Other Customer Characteristics. Energy J. 2014, 35. [CrossRef]

17. Joo, J.Y.; Ahn, S.H.; Yoon, Y.T.; Choi, J.W. Option Valuation Applied to Implementing Demand Response via Critical Peak Pricing. In Proceedings of the 2007 IEEE Power Engineering Society General Meeting, Tampa, FL, USA, 24-28 June 2007.

18. Park, S.C.; Jin, Y.G.; Song, H.Y.; Yoon, Y.T. Designing a Critical Peak Pricing Scheme for the Profit Maximization Objective Considering Price Responsiveness of Customers. Energy 2015, 83, 521-531. [CrossRef]

19. Park, S.; Jin, Y.; Yoon, Y. Designing a Profit-Maximizing Critical Peak Pricing Scheme Considering the Payback Phenomenon. Energies 2015, 8, 11363-11379. [CrossRef]

20. Zhang, Q.; Wang, X.; Fu, M. Optimal Implementation Strategies for Critical Peak Pricing. In Proceedings of the 6th International Conference on the European Energy Market, Leuven, Belgium, 27-29 May 2009.

21. Chen, W.; Wang, X.; Petersen, J.; Tyagi, R.; Black, J. Optimal Scheduling of Demand Response Events for Electric Utilities. IEEE Trans. Smart Grid 2013, 4, 2309-2319. [CrossRef]

22. Zhang, X. Optimal Scheduling of Critical Peak Pricing Considering Wind Commitment. IEEE Trans. Sustain. Energy 2014, 5, 637-645. [CrossRef]

23. Lee, S.Y.; Jin, Y.G.; Yoon, Y.T. Determining the Optimal Reserve Capacity in a Microgrid with Islanded Operation. IEEE Trans. Power Syst. 2016, 31, 1369-1376. [CrossRef]

24. Ilic, M.; Skantze, P.; Yu, C.N.; Fink, L.; Cardell, J. Power Exchange for Frequency Control (PXFC). In Proceedings of the IEEE Power Engineering Society. 1999 Winter Meeting (Cat. No.99CH36233), New York, NY, USA, 31 January-4 February 1999.

25. Kim, S.W. A Devolved Scheme of Active Distribution System Operators for Utilizing Flexibility Options under Market Environment. Ph.D. Thesis, Seoul National University, Seoul, Korea, 2018.

26. Song, Y.H. Day-ahead Imbalance Band Market Operation of Transmission System Operator Considering Devolution of Balancing Responsibility. Ph.D. Thesis, Seoul National University, Seoul, Korea, August 2019.

27. Australian Energy Market Operator. Causer Pays Procedure Factors for Asynchronous Operation, Australia. 2017. Available online: https://www.aemo.com.au/-/media/Files/Stakeholder_Consultation/Consultations/ Electricity_Consultations/2017/Causer-Pays/Causer-Pays-Asynchronous-operation-final-report.pdf (accessed on 21 November 2019).

28. Wisconsin Public Service, Wisconsin Electric Rates and Programs. Available online: https://accel. wisconsinpublicservice.com/home/response_rewards.aspx (accessed on 17 September 2019).

29. Minnesota Power, Critical Peak Pricing. Available online: https://www.mnpower.com/CustomerService/ TODCriticalPeakPricing (accessed on 17 September 2019).

30. Fleten, S.E.; Wallace, S.W. Stochastic Programming Models in Energy. Handb. Oper. Res. Manag. Sci. 2003, 10, 637-677. 
31. Ding, T.; Hu, Y.; Bie, Z. Multi-Stage Stochastic Programming with Nonanticipativity Constraints for Expansion of Combined Power and Natural Gas Systems. IEEE Trans. Power Syst. 2018, 33, 317-328. [CrossRef]

32. Ruszczyski, A. Decomposition methods in stochastic programming. Math. Program 1997, 79, $333-353$. [CrossRef]

33. Silvente, J.; Kopanos, G.M.; Pistikopoulos, E.N.; Espuña, A. A Rolling Horizon Optimization Framework for the Simultaneous Energy Supply and Demand Planning in Microgrids. Appl. Energy 2015, 155, 485-501. [CrossRef]

34. Li, Z.; Ierapetritou, M.G. Rolling Horizon Based Planning and Scheduling Integration with Production Capacity Consideration. Chem. Eng. Sci. 2010, 65, 5887-5900. [CrossRef]

35. Zamarripa, M.; Marchetti, P.A.; Grossmann, I.E.; Singh, T.; Lotero, I.; Gopalakrishnan, A.; Besancon, B.; André, J. Rolling Horizon Approach for Production-Distribution Coordination of Industrial Gases Supply Chains. Ind. Eng. Chem. Res. 2016, 55, 2646-2660. [CrossRef]

36. Zakariazadeh, A.; Jadid, S.; Siano, P. Integrated Operation of Electric Vehicles and Renewable Generation in a Smart Distribution System. Energy Convers. Manag. 2015, 89, 99-110. [CrossRef]

37. Wang, X.; Palazoglu, A.; El-Farra, N.H. Operational Optimization and Demand Response of Hybrid Renewable Energy Systems. Appl. Energy 2015, 143, 324-335. [CrossRef]

38. The World Bank. Primer on Demand-Side Management with an Emphasis on Price-Responsive Programs. 2005. Available online: http://siteresources.worldbank.org/INTENERGY/Resources/PrimeronDemandSideManagement.pdf (accessed on 17 September 2019).

39. Huisman, R.; Huurman, C.; Mahieu, R. Hourly Electricity Prices in Day-Ahead Markets. Energy Econ. 2007, 29, 240-248. [CrossRef]

40. Shabbir, A. Multistage Stochastic Optimization. Georgia Tech, USA, 2016. Available online: https: //www.ima.umn.edu/materials/2015-2016/ND8.1-12.16/25386/mssp.pdf (accessed on 17 September 2019).

41. Nguyen, D.T.; Le, L.B. Optimal Bidding Strategy for Microgrids Considering Renewable Energy and Building Thermal Dynamics. IEEE Trans. Smart Grid 2014, 5, 1608-1620. [CrossRef]

42. Moghimi Ghadikolaei, H.; Ahmadi, A.; Aghaei, J.; Najafi, M. Risk Constrained Self-Scheduling of Hydro/Wind Units for Short Term Electricity Markets Considering Intermittency and Uncertainty. Renew. Sustain. Energy Rev. 2012, 16, 4734-4743. [CrossRef]

43. Lorenz, E.; Hurka, J.; Heinemann, D.; Beyer, H.G. Irradiance Forecasting for the Power Prediction of Grid-Connected Photovoltaic Systems. IEEE J. Sel. Top. Appl. Earth Obs. Remote Sens. 2009, 2, 2-10. [CrossRef]

44. Ziadi, Z.; Oshiro, M.; Senjyo, T.; Yona, A.; Urasaki, N.; Funabashi, T.; Kim, C.H. Optimal Voltage Control Using Inverters Interfaced with PV Systems Considering Forecast Error in a Distribution System. IEEE Trans. Sustain. Enerigy 2014, 5, 682-690. [CrossRef]

45. Da Silva, A.P.A.; Moulin, L.S. Confidence Intervals for Neural Network Based Short-Term Load Forecasting. IEEE Trans. Power Syst. 2000, 15, 1191-1196. [CrossRef]

46. Sahin, C.; Shahidehpour, M.; Erkmen, I. Allocation of Hourly Reserve Versus Demand Response for Security-Constrained Scheduling of Stochastic Wind Energy. IEEE Trans. Sustain. Energy 2013, 4, 219-228. [CrossRef]

47. PJM, Energy Market. Available online: https://www.pjm.com/markets-and-operations/energy.aspx (accessed on 17 September 2019).

48. Elia, Solar-PV Power Generation Data. Available online: https://www.elia.be/en/grid-data/power-generation/ Solar-power-generation-data/Graph (accessed on 17 September 2019).

49. Burer, S.; Letchford, A.N. Non-Convex Mixed-Integer Nonlinear Programming: A Survey. Surv. Oper. Res. Manag. Sci. 2012, 17, 97-106. [CrossRef]

50. Razali, N.M.M.; Hashim, A.H. Backward Reduction Application for Minimizing Wind Power Scenarios in Stochastic Programming. In Proceedings of the 4th International Power Engineering and Optimization Conference (PEOCO), Shah Alam, Malaysia, 23-24 June 2010.

(C) 2019 by the authors. Licensee MDPI, Basel, Switzerland. This article is an open access article distributed under the terms and conditions of the Creative Commons Attribution (CC BY) license (http://creativecommons.org/licenses/by/4.0/). 